\title{
Original article \\ Assessment of Factors Contributing to Medicine Expiry in Rwanda: Case of the Medical Procurement and Production Division
}

Theogene Hakuzimana ${ }^{1}{ }^{2 *}$, Pierre Claver Kayumba ${ }^{1}$, Innocent Hahirwa ${ }^{3}$, Max Kabalisa ${ }^{4}$

${ }^{1}$ EAC Regional Centre of Excellence for Vaccines, Immunization, and Health Supply Chain Management, College of Medicine and Health Sciences, University of Rwanda, Kigali, Rwanda. ${ }^{2}$ Ministry of Health, Kigali, Rwanda.

${ }^{3}$ College of Medicines and Health Sciences, University of Rwanda, Kigali, Rwanda.

${ }^{4}$ USAID/Global Health Supply Chain-Procurement and Supply Management Project, Kigali, Rwanda.

*Corresponding Author: Theogene Hakuzimana. EAC Regional Centre of Excellence for Vaccines, Immunization, and Health Supply Chain Management, College of Medicine and Health Sciences, University of Rwanda, Kigali, Rwanda. Email: theohak09@gmail.com

\section{Abstract}

\section{Background}

Regardless of the significant efforts used and put in place to enhance supply chain performance in Rwanda, there is still poor inventory management and big loss due to expiry of medicines at Medical Procurement and Production Division (MPPD).

\section{Objective}

To assess the factors that contributes to expiry of medicines at MPPD and formulate recommendations for the improvement of the current situation.

\section{Methods}

This is a descriptive cross-sectional study used for 25 respondents. A questionnaire containing closed-ended questions was used focusing on factors contributing to expiries of medicines for each product category managed by MPPD from 2014-2018. Additionally, the researcher reviewed all inventory reports, including expiries for the same period under study. The study focused on targeting respondents working at MPPD as pharmacists both technical and administrative, also other non-pharmacist working in the warehouse were considered as respondents. The hard copy of questionnaire was handed over to 26 respondents and requested to provide filled questionnaire within seven days. Twenty-five respondents were able to return the filled questionnaire on time, giving $96 \%$ response rate.

\section{Results}

The study found that in MPPD, medicines are still expiring. During five years (from 2014 up to 2018) the total expired products were valued at RWF $6,046,778,655$ for all program categories: HIV commodities had the largest share 53.3\%, Essential Medicines 22.5\%, Malaria 13\%, Maternal Child Health commodities 5.7\%, Products used for Community health workers $4.5 \%$, TB products $1 \%$ and $0.1 \%$ for Family Planning products. The study found that major contributing factors for expiry of health commodities at MPPD, are ranked as follows: Supply chain management $90 \%$, other factors $73 \%$, Poor storage management 68\% and Excessive drug supply $67 \%$. 


\section{Conclusion}

Considering the study results, it looks like no significant effect of excessive drug supply and inventory management on the expiration of medicines at MPPD. However, the Supply Chain Management components are the most vulnerable to contribute to the expiration of medicines at MPPD. There are many changes to be done inside the institution to remedy the issue of expiration like working according to the standard operating procedures, improving the Skills of personnel in supply chain management, empowering the procurement unit with skilled personnel and improving the communication with stakeholders to facilitate the smooth and quick replenishment and distribution of the stock.

Rwanda J Med Health Sci 2021;4(2): 281-291

Keywords: medicine expiry, assessment and factors, Central Medical Store

\section{Background}

Medicines are very crucial for a wellfunctioning healthcare system all over the world. There is a challenge of the huge volume of expired medicines accumulates worldwide because of over-prescription, combined with overproduction of medicines.[1] Most products are distributed to pharmacies expiring in 1 to 5 years from the date they have been manufactured, in case of drugs stored in temporary, provisional warehouses as in emergency settings. However, it is very hard to rely on the quoted expiry date because drugs cannot be used beyond the expiry date.[2]

Therefore, the expiration date that we see may not necessarily be the drug's real shelf life. [3] In Kenya, Tull (2018) confirms that a drug repackaging scam was stopped by the Kenyan police in April 2018, according to media reports. The Kenya Medical Supplies Authority lost drugs valued at Sh352 million (USD3.47 million) due to expiry or damage in one year alone.

The 2016/17 KEMSA report did not explain expired stocking drugs, thereby causing unnecessary loss to the authority when numerous hospitals complained of a shortage of drugs.[3]

In Uganda, a cross-sectional study of six public and 32 private medicine outlets in Kampala and Entebbe municipality was conducted. Results revealed that drugs and medicines that are highly expiring include those for vertical programs, donated drugs, and those used at the lowest rate. Even essential medicines, the study revealed that most of the time, expire in the supply chain.[4] In developing countries, the budgets allocated to medicines are always high and are even the second category of expense after human resource,[5] that is why the supply chain needs to be improved and sustained to prevent any loss, including pilferage, misuse and expiry. Nakyanzi indicated that medicines expiration always leads to the significant loss of economies, resulting in a shortage of medicines. Therefore, the negative impact on the quality of healthcare provided to patients and people lose confidence in their health system. [4] This is reflected in Rwanda's case as reported by USAID-DELIVER Final Report 2016 that, for many years, medicines' supply chain in Rwanda knew much inefficiency-from poor quantification, fragmented 
distribution, and the inexistence of a harmonized logistics information system in health. USAID-DELIVER Final Report 2016 continues to indicate that this has led to a disruption in the health commodity supply chain.[6] The government's ability to achieve its health goals has been compromised. The remediation of these problems has been establishing new strategies by the Government of Rwanda (GOR) and the partnership with stakeholders to make more strong and sustainable its supply chain management. While in Rwanda, the public health supply chain knew substantive gains in availing products and strengthening information visibility, the MOH still recognizes that satisfying the needs of the future population requires a very powerful and continuous review of activities and new supply chain investments.

Literature shows that from 2008, there had been an increase in the value of the health commodities treated per year; it raised from $\$ 3.3$ million to $\$ 50$ million, and the trends is gradually increasing. [6] This might explain clearly why having a robust supply chain represents an essential strategy for a satisfying availability of necessary health commodities in Rwanda and therefore, sustainable availability of essential medicines with less or no expiry of medicines. Medicines expiry in the supply chain highlights a problem, which may include medicine selection, quantification, procurement, storage, distribution, use and the entire supply chain management and policies.

Medical production and procurement division (MPPD) is the only central medical store named as public. Based on its mandate of availing all medical supplies in Rwanda, MPPD might be encountering challenges in producing, procuring and distributing medical supplies that might lead to medicines expiry. Hence, conducting a study on factors contributing to medicines expiry in MPPD seems to be highly needed as there is no kind of research conducted in Rwanda. Consequently, the main objective of this study is to assess the factors that contribute to expiry of medicines at Medical Procurement and Production Division and provide recommendations to address identified factors to ensure minimal loss due to expiries of medicines.

\section{Methods \\ Study setting}

At Rwanda's central medical store, the study location was in Kigali; Medical Procurement and Production Division (MPPD). A division in Rwanda Biomedical Center and the main supply entity named public by which big volume of medicines are flowing through the system can avail these medicines at all decentralized level (Provincial, District and Community). It is located at Kacyiru in Gasabo District near National Police Headquarters.

\section{Study design}

Descriptive research design has been used in this study. Descriptive research accurately describes the participants (Crossman, 2013). A descriptive study was deemed appropriate when the target population was large, and respondents could be obtained using random sampling, such as a stratified random sampling technique. 
The population of the study consisted of 18 pharmacists and 22 other personnel working in the warehouse including key administrative staff at MPPD. The sample size was a convenient method among the target population selected because they carry specific responsibilities and management of day-to-day warehouse operations. The researcher approached 50 staff from MPPD and only 26 staff volunteered to participate in the study.

\section{Data collection instrument and procedure}

The research used a questionnaire containing closed-ended questions and a researched developed an excel tool to collect and analyze the value of expired drugs during the last five years from 2014 to 2018. There questions were multiple choices where respondents were asked to tick suitable choices in the questionnaire. The tool was designed to include all the things that helped to achieve the research objectives.

Reliability requires the standard of measurement as quoted by Kothari (2006), who says that reliability is the accuracy or repeatability of the measurements in their daily senses, while validity concerns whether the concept measures the study's main purpose.

For the confirmation of validity and accuracy of the research tool, five questionnaires were distributed to the staff of MPPD to check the process of data collection; however, these respondents for pretest were not included in the responds for the research. High considerations were made to prevent bias, while testing the questionnaire the responds were not informed if the study will be conducted at MPPD. Careful considerations were made not to include pre-test respondents in the real research study at MPPD. Upon completion of pre-test the questionnaire was revised to address identified gaps and the study commenced within one month after pretest.

\section{Data analysis}

The data was edited, coded, and classified to systematically and present the data analysis results. The questionnaire's data were analyzed using the Statistical Package for the Social Sciences (SPSS) and MS excel. Data on expired medicines has been filtered and treated to find significant information to present in tables and pie charts. Descriptive statistics were used. The data was presented in a diagrammatic manner using pie charts and tables.

\section{Ethical consideration}

Ethical considerations have been observed. This meant obtaining the requisite approval from both the University of Rwanda-College of Medicine and Health Sciences (IRB) and the Ministry of Health. Their permission is useful in ensuring that this research study was completed successfully so that the results obtained in the subsequent stages do not contravene the rules and regulations laid down in the conduct of this research. The authorizations have also helped to guarantee the confidentiality of responses from respondents who participated in the study. 


\section{Results}

Socio-demographic characteristics

The results indicated that 14 (56\%) were male, while 11 (44\%) were female, as displayed in table 1.

Table 1. Participants Demographic Information (n=25)

\begin{tabular}{llll}
\hline Variables & Characteristics & Frequency & Percentage \\
\hline Gender & Male & 14 & 56 \\
& Female & 11 & 44 \\
\hline \multirow{4}{*}{ Age } & $20-30$ & 0 & 0 \\
& $31-40$ & 16 & 64 \\
& $41-50$ & 6 & 24 \\
& $51-60$ & 3 & 12 \\
& Above 60 & 0 & 0 \\
Educational & Secondary & 0 & 0 \\
Qualification & Diploma & 0 & 0 \\
& Bachelor & 16 & 64 \\
& Masters & 9 & 36 \\
& Others & 0 & 0 \\
Years of Service & Less than 1 year & 0 & 0 \\
& $1-5$ & 6 & 24 \\
& Above 10 & 7 & 28 \\
\hline
\end{tabular}

\section{Factors for expiry of medicines}

While identifying the major contributing factors for expiry of health commodities at MPPD, combining strongly agree and agree, table 2 indicates that respondents ranked

Table2. Staff's understanding of the major contributing factors for expiry of health commodities at MPPD $(n=25)$

\begin{tabular}{|c|c|c|c|c|c|c|}
\hline \multirow[t]{2}{*}{ Factors contributing to Expiries } & $\begin{array}{l}\text { Strong } \\
\text { ly } \\
\text { agree }\end{array}$ & $\begin{array}{l}\text { Agr } \\
\text { ee }\end{array}$ & $\begin{array}{l}\text { No } \\
t \\
\text { su } \\
\text { re }\end{array}$ & $\begin{array}{l}\text { Disag } \\
\text { ree }\end{array}$ & $\begin{array}{l}\text { stron } \\
\text { gly } \\
\text { disag } \\
\text { ree }\end{array}$ & Total \\
\hline & $\%$ & $\%$ & $\%$ & $\%$ & $\%$ & $\%(n)$ \\
\hline \multicolumn{7}{|l|}{ 1. Excessive Drug Supply } \\
\hline $\begin{array}{l}\text { Excessive inventory results in } \\
\text { expiries }\end{array}$ & 32 & 28 & 8 & 12 & 20 & $\begin{array}{l}100 \\
(25)\end{array}$ \\
\hline $\begin{array}{l}\text { Knowledge of Quantification and } \\
\text { supply planning }\end{array}$ & 40 & 36 & 12 & 4 & 8 & $\begin{array}{l}100 \\
(25)\end{array}$ \\
\hline
\end{tabular}
management $90 \%$, other factors $73 \%$, poor storage management $68 \%$ and excessive drug supply $67 \%$.

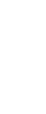

A large number of the respondents $(64 \%)$ have the ages between $31-40$.

factors as follows: supply chain 


\begin{tabular}{|c|c|c|c|c|c|c|}
\hline Factors contributing to Expiries & $\begin{array}{l}\text { Strong } \\
\text { ly } \\
\text { agree }\end{array}$ & $\begin{array}{l}\text { Agr } \\
\text { ee }\end{array}$ & $\begin{array}{l}\text { No } \\
\text { t } \\
\text { su } \\
\text { re }\end{array}$ & $\begin{array}{l}\text { Disag } \\
\text { ree }\end{array}$ & $\begin{array}{l}\text { stron } \\
\text { gly } \\
\text { disag } \\
\text { ree }\end{array}$ & Total \\
\hline & $\%$ & $\%$ & $\%$ & $\%$ & $\%$ & $\%(n)$ \\
\hline $\begin{array}{l}\text { Knowledge of Distribution of } \\
\text { Medicines }\end{array}$ & 80 & 12 & 4 & 0 & 4 & $\begin{array}{l}100 \\
(25)\end{array}$ \\
\hline $\begin{array}{l}\text { Coordination between procurement } \\
\text { and Warehousing team at MPPD }\end{array}$ & 16 & 24 & 32 & 16 & 12 & $\begin{array}{l}100 \\
(25)\end{array}$ \\
\hline \multicolumn{7}{|l|}{ 2. Poor Inventory Management } \\
\hline $\begin{array}{l}\text { Poor storage conditions affect the } \\
\text { expiry of medicines }\end{array}$ & 16 & 4 & 24 & 24 & 32 & $\begin{array}{l}100 \\
(25)\end{array}$ \\
\hline $\begin{array}{l}\text { The methods of storage of drug are } \\
\text { appropriate }\end{array}$ & 48 & 52 & 0 & 0 & 0 & $\begin{array}{l}100 \\
(25)\end{array}$ \\
\hline $\begin{array}{l}\text { Drugs are stored according to the } \\
\text { date procured }\end{array}$ & 12 & 20 & 28 & 24 & 16 & $\begin{array}{l}100 \\
(25)\end{array}$ \\
\hline $\begin{array}{l}\text { All drugs are stored according to the } \\
\text { prescribed storage conditions }\end{array}$ & 52 & 40 & 0 & 8 & 0 & $\begin{array}{l}100 \\
(25)\end{array}$ \\
\hline $\begin{array}{l}\text { Room temperature is always } \\
\text { monitored }\end{array}$ & 72 & 24 & 4 & 0 & 0 & $\begin{array}{l}100 \\
(25)\end{array}$ \\
\hline \multicolumn{7}{|l|}{ 3. Supply Chain Management } \\
\hline Standard operating procedures & 92 & 8 & 0 & 0 & 0 & $\begin{array}{l}100 \\
(25)\end{array}$ \\
\hline Skills in supply chain Management & 76 & 8 & 8 & 8 & $\mathbf{0}$ & $\begin{array}{l}100 \\
(25)\end{array}$ \\
\hline Management Information system & 56 & 32 & 8 & 4 & 0 & $\begin{array}{l}100 \\
(25)\end{array}$ \\
\hline Active Distribution of products & 80 & 4 & $\mathbf{0}$ & $\mathbf{0}$ & 16 & $\begin{array}{l}100 \\
(25)\end{array}$ \\
\hline Procurement & 92 & 0 & 4 & 0 & 4 & $\begin{array}{l}100 \\
(25)\end{array}$ \\
\hline Communication with stakeholders & 88 & 4 & $\mathbf{0}$ & 4 & 4 & $\begin{array}{l}100 \\
(25) \\
\end{array}$ \\
\hline \multicolumn{7}{|l|}{ 4. Other factors } \\
\hline Donations management & 16 & 52 & 28 & 0 & 4 & $\begin{array}{l}100 \\
(25)\end{array}$ \\
\hline $\begin{array}{l}\text { Short shelf life products especially } \\
\text { Lab commodities }\end{array}$ & 40 & 32 & 4 & 24 & 0 & $\begin{array}{l}100 \\
(25)\end{array}$ \\
\hline $\begin{array}{l}\text { Expensive medicines that are } \\
\text { utilized due to none ordering or } \\
\text { bought for emergency }\end{array}$ & 44 & 28 & 4 & 12 & 12 & $\begin{array}{l}100 \\
(25)\end{array}$ \\
\hline $\begin{array}{l}\text { Abrupt cessation of use/treatment } \\
\text { policy change/new treatment } \\
\text { protocol }\end{array}$ & 48 & 32 & 12 & 4 & 4 & $\begin{array}{l}100 \\
(25)\end{array}$ \\
\hline
\end{tabular}




\section{Value of expired products}

Table 3 shows the value in Rwandan francs of expired medicines by category

Table 3. Value of Expired Product in Rwanda Francs during the Period 2014-

2018

\begin{tabular}{llllll}
\hline Product & \multicolumn{5}{l}{ Value of expired Products in RWF (2014-2018) } \\
\cline { 2 - 6 } & $\mathbf{2 0 1 4}$ & $\mathbf{2 0 1 5}$ & $\mathbf{2 0 1 6}$ & $\mathbf{2 0 1 7}$ & $\mathbf{2 0 1 8}$ \\
\hline HIV & $677,034,97$ & $957,440,36$ & $585,952,16$ & $402,547,7$ & $596,676,4$ \\
COMMODITI & 9 & 5 & 3 & 14 & 68 \\
ES & & & & & \\
PF & 228,735 & 554,125 & 857,585 & - & $3,258,472$ \\
MALARIA & $168,872,75$ & $204,876,91$ & $397,038,31$ & $5,583,762$ & $6,894,068$ \\
& 9 & 1 & 8 & & \\
TB & $7,170,512$ & $15,516,848$ & 20,740857 & $1,494,560$ & $14,501,32$ \\
& & & & & 8 \\
MCCH & $140,490,04$ & $120,100,55$ & $10,775,441$ & $6,021,672$ & $65,766,70$ \\
& 7 & 5 & & & 2 \\
ESSENTIAL & $662,873,25$ & $354,927,58$ & $210,339,35$ & $103,711,4$ & $29,507,64$ \\
MEDS & 4 & 2 & 1 & 70 & 9 \\
SC & $3,620,471$ & $230,334,28$ & $5,882,810$ & - & $31,186,84$ \\
& & 3 & & & 5 \\
\hline TOTAL & $1,660,290,7$ & $1,883,750,6$ & $1,235,586,5$ & $519,359,1$ & $747,791,5$ \\
& 57 & 69 & 25 & 78 & 26 \\
\hline
\end{tabular}

\section{Expired products by program} category

Figure 1 shows that during the period of this study, every year, HIV commodities were the most expiring in the store of MPPD followed by the drugs called essential medicines at during the period of five years from 2014 to 2018 in Medical Procurement and Production Division. 


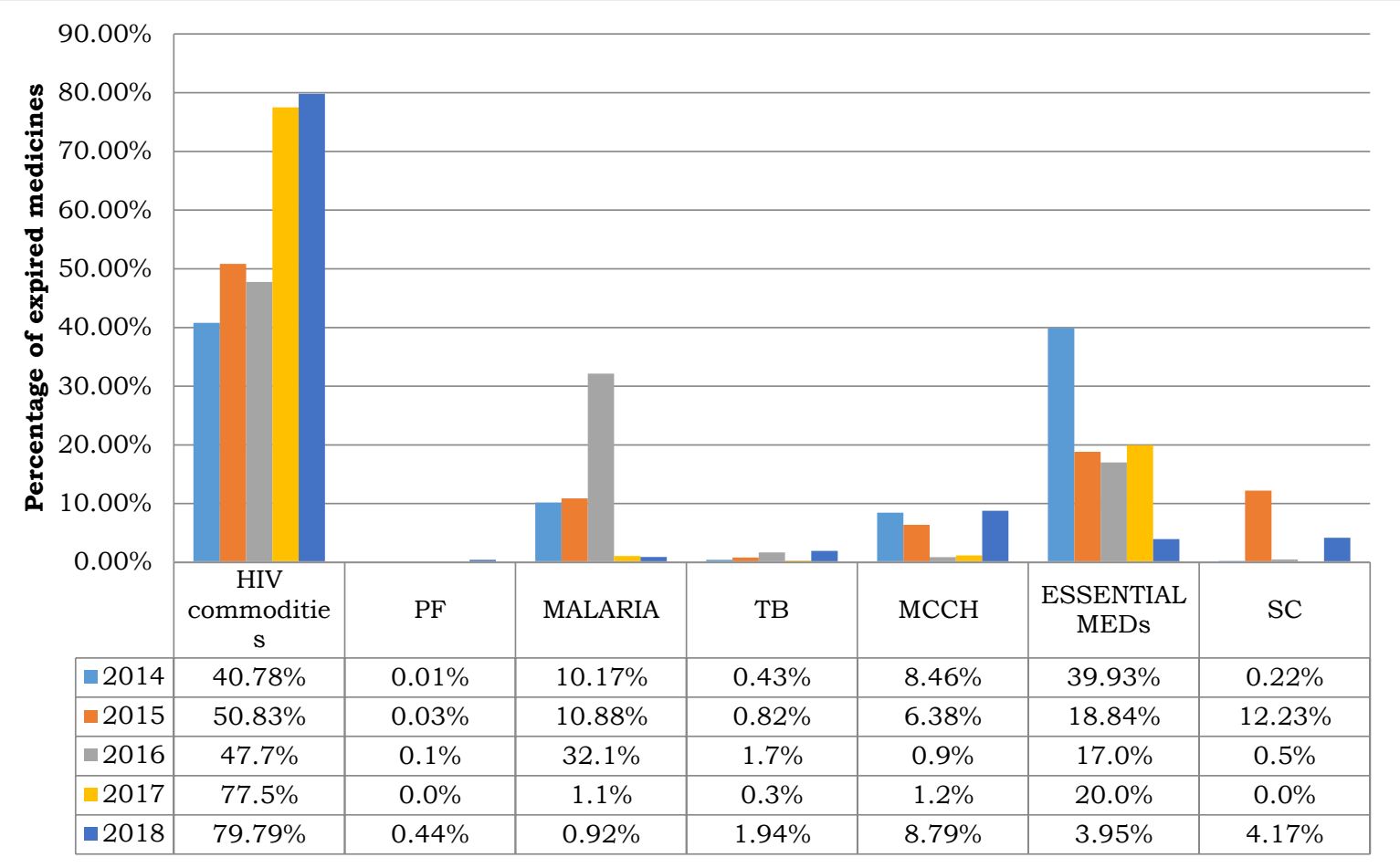

\section{Figure 1. Expired Products by Program Category per year}

Figure 2 also shows that during the period of this study, HIV commodities occupied a half of all expiries in the store of MPPD with 53\% followed essential medicines with $23 \%$ and in the third position there are Malaria commodities with $13 \%$. Family planning and Tuberculosis commodities were the less expiring commodities when considering the expiration with even a percentage reaching zero expiries.

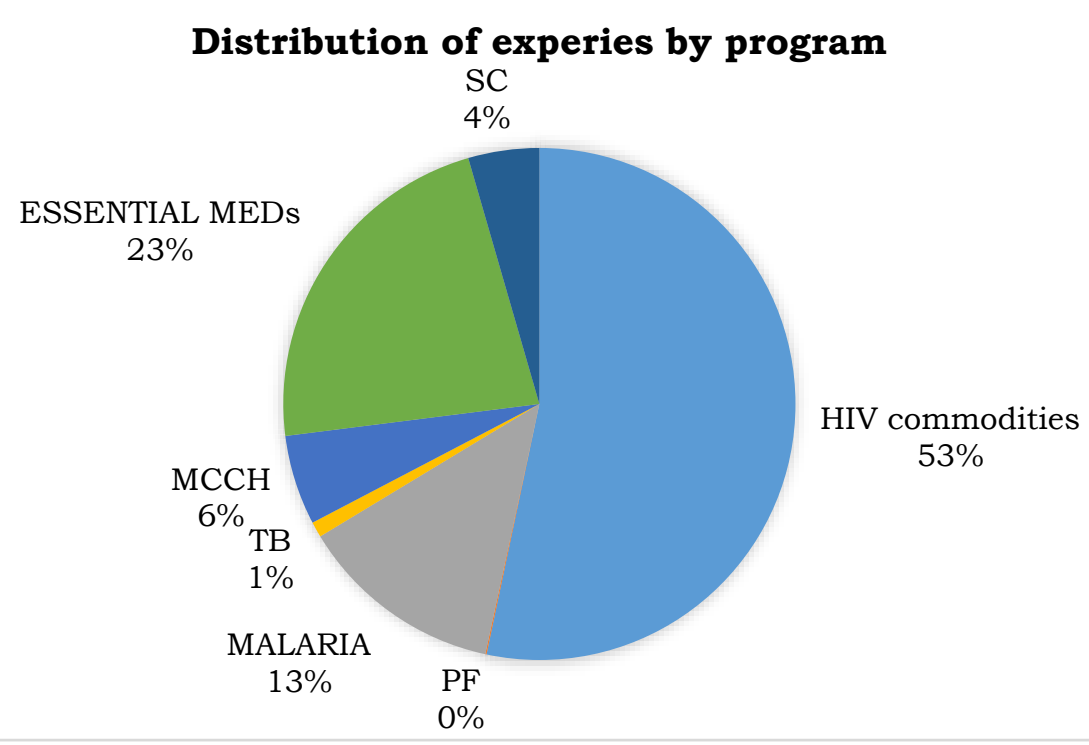

Figure 2. The share of expired products by Product Category 


\section{Discussion}

\section{Factors contributing to the expiry of health commodities}

Excessive Drug Supply and Inventory Management's effects on the expiration of medicines at MPPD are low compared to Supply Chain Management components. This is in concordance with literature saying that poor quantification practices and donors ordering large quantities of drugs without collaborating with the departmental user inputs contributed to large quantities of expired drugs in many countries.[7]

This study found that major contributing factors for expiry of health commodities at MPPD were related to supply chain management (e.g: selection, ordering, and supply planning), poor storage management and Excessive drug supply. This is in line with Nakyanzi, who reported that best coordination of government projects or vertical programs and public stores of health commodities can improve the problem of overstocking which is mainly associated with duplicated procurement, and of course, the harmonization of medicine quantification with habits in prescription and preferences of patients to ensure supply matches turnover.[4] Other studies also revealed an inadequate ordering and review process to be associated with expiration of medicines in different health facilities.[8]

\section{Value of Expired Product}

As revealed in this study, and also similar to previous studies, wastage of money when incinerating medicines is a global challenge.[5] The current study reported a very high value of expired products. This is a big challenge considering the economic status of Rwanda and health spending. Although there is a remarkable reduction in expiry for the last two years of almost two folds, a lot still needs to be done to avoid this level of wastages. The researcher suggested that during quantification at MPPD, multidisciplinary team should sit and work together in determination of quantities to be procured in regard of minimization of unnecessary quantities that may expire. $\mathrm{He}$ also revealed that storage conditions should be monitored and reported to minimize the returned products that expire because they have been refused by users. An attention should be kept when receiving donations because they sometimes near to expire. Products with short shelf life should be procured in quantities to direct distributed to the clients to be used before their expiration.

A well-managed drug supply chain management may reduce the frequency and the quantity of the expired drug. Therefore, future studies may explore other factors that contribute to the expiry of medicines that may be out of what was included in the current study. These may include leadership and accountability of the institution and maybe how customer relationship management is done at MPPD.

\section{Conclusion}

The study has revealed that supply chain management related factors (selection, ordering, and supply 
planning), poor storage conditions, excess drug supply, and other factors including abrupt change in the policy of use/treatment, short shelf life of medicines, expensive medicine and management of donation, affect the expiry of medicines at MPPD. Besides, this study also reported a very high value of expired products which is a cause of concern and should be addressed.

\section{Conflict of interest}

All authors report no conflict of interest.

\section{Acknowledgement}

The authors of this paper gratefully acknowledge the funding of the Masters of Health Supply Chain Management by the German Federal Ministry for Economic Cooperation and Development (BMZ) through KfW Development Bank and the East African Community Regional Center of Excellence for Vaccines, Immunization, and Health Supply Chain Management. In addition, this research would not have been possible without the assistance of the College of Medicine and Health Sciences, University of Rwanda. We are also thankful to the management of MPPD and all the participants in the research for facilitating this study.

\section{Authors' contribution}

TH was responsible for the study conception, design, and data analysis. MK contributed in searching literature to support the discussion of key findings. PCK, IH and MK contributed in reviewing comments, drafting, proofreading as well as editing of the manuscript. All authors have read and approved the final copy of the manuscript.
This article is published open access under the Creative Commons Attribution-NonCommercial NoDerivatives (CC BYNC-ND4.0). People can copy and redistribute the article only for noncommercial purposes and as long as they give appropriate credit to the authors. They cannot distribute any modified material obtained by remixing, transforming or building upon this article. See https://creativecommons.org/licenses/by-ncnd/4.0/

\section{References}

1. Alnahas F, Yeboah P, Fliedel L, Abdin AY, Alhareth K. Expired medication: Societal, regulatory and ethical aspects of a wasted opportunity. Int. J. Environ. Res. Public Health. 2020; 17(3):787.

2. Mashishi KA. Expiration of drugs in public hospital pharmacies of sekhukhune district, Limpopo province, South Africa.University of Limpopo. 2015.

3. Tull K. Drug expiry standards in developing countries. K4D Knowledge, evidence and learning for development. Helpdesk Report. 2018.

4. Nakyanzi JK, Kitutu FE, Oria H, Kamba PF. Expiry of medicines in supply outlets in Uganda. Bull World Health Organ. 2010 Feb; 88(2): 154-158.

5. Celeste S. Trend in revenue loss due to expired medication at a large urban hospital in Johannesburg, South Africa. WireDSpace, Wits institutional Repository environment on DSpace. 2016. 
6. USAID | deliver project. USAID I deliver project Final Country Report Rwanda. Arlington, Va.: USAID | deliver project, Task Order 4 and Task Ordr 7. 2016.

7. Gebremariam ET, Gebregeorgise DT, Fenta TG. Factors contributing to medicines wastage in public health facilities of South West Shoa Zone, Oromia Regional State, Ethiopia: a qualitative study. Journal of Phamraceutical Policy and Practice. 2019; 12:29
8. Trueman P, Taylor DG, Lowson K, Bligh A, Meszaros A, Wright $\mathrm{D}$, et al. Evaluation of the Scale , Causes and Costs of Waste Medicines. 